\title{
THE STUDY OF THEORY IN MUSIC TEACHING. IS IT SOUND?
}

\section{By A. REDGRAVE CRIPPS}

$\mathrm{W}^{\mathrm{n}}$

$\mathrm{E}$ are fond of congratulating ourselves on the progress made within recent years in music; and, be it said at once, not without cause. There is one respect, however, in which little if any progress has been made: and unfortunately it is the most important of all, since it underlies everything else. It is in the teaching of music.

Assuming, for the moment, that the fact is as stated, let us consider the reason for it. It lies on the surface. Improved methods of education are not generally thought of in the abstract. but nearly always in connection with some particular subject: some time, therefore, must always elapse before they are applied to other subjects. Music has somehow a position by itself; and it is not, therefore, to be wondered at, that music teaching has hardly been touched by the new spirit which has within recent years entered into education.

What, then, are our present methods? It is not very easy to answer this question quite definitely. There must always be a certain amount of diversity in teaching, just as there is in the individual characteristics of the teachers themselves. But, apart from minor differences, which are comparatively small and unimportant, there is a general agreement as to what is (within limits) the proper way of teaching music. There are certain general underlying ideas that practically all teachers have in common; ideas which are, in fact, almost taken for granted.

We may, perhaps, take the course of study at our great schools of music as fairly representing our present teaching. We find that in all of these the pupil's studies are divided into two kinds: the practical and the theoretical. By the practical is meant lessons in the principal and second studies, whatever they may be (such as singing, piano-playing, etc.); by the theoretical is meant lessons in Harmony, Counterpoint, etc. With the first of these-the practical-we need not for the present concern ourselves; the lessons which the pupil receives in these will, obviously, only affect him directly in these particular subjects. 
The theoretical course, as we have just said, is divided into separate studies, such as Harmony, Counterpoint, and (when the student is more advanced) Canon, Fugue, etc. Now it should be noticed in the first place (and the point is important) that this division is entirely artificial, and does not exist in actual music. We may speak of Harmony and Counterpoint and Melody and Rhythm as if they were separate things, but in reality they are so inextricably mingled together that it is quite impossible to separate them,-even in thought. (Even the simplest music consists of more than one of these, and in more advanced works the various elements of effect are often so compounded together that one without the others would be absolutely meaningless.) What justification, then, is there for separating them in study?

It is true that music may, on analysis, be reduced roughly to certain constituents (though other elements enter into it which the theorist generally takes no note of, such as the peculiar tone quality of the various instruments, etc.); but that is surely no reason why those constituents should be studied separately. But not only are these subjects taught quite separately, they are taught as if they really were separate, -one might almost say, as if they were in opposition to each other. How often, for instance, is the pupil told that a certain chord or progression is allowable in Harmony, but not in Counterpoint. Nothing could be worse than this. Not only does it (as has been said) separate the two things most completely in the student's mind, but it has another and even worse effect. He comes to think that the only test of the rightness or wrongness of anything he has written is whether or no it conforms to the "rules" of some particular branch of theory; whereas the real test is, of course, (to put it roughly) "Does it sound well?"

But however separate these studies may seem to the student, they have at least one thing in common: viz., that none of them has any real relation to actual music. That this is so is clear even in the case of Harmony exercises. But in Harmony exercises it is not so much because they are different to real music, as because they show only one side of real music, - the relation of chords; they might possibly-some of them-be taken for rather dull hymn tunes. But what is to be said of "Strict Counterpoint"? Here the want of relation with actual composition arises simply from the fact that the two things have nothing whatever to do with each other. The exercises which the student has to write have no resemblance to any music that ever existed; they cannot be sung by any combination of voices or played by any combination 
of instruments. They are, in fact, paper music, pure and simple; mere combinations of notes fitted in one against the other (like a Chinese puzzle) in accordance with certain arbitrary rules. Indeed, this study of Strict Counterpoint is so utterly artificial, and so far removed from all real art work, that one almost wonders what it can possibly be founded on-how it ever came to exist at all. As a matter of fact it is simply a survival of the ancient teaching of music.

Mr. Rockstro at the beginning of his little book on Counterpoint gives a list of authorities (whom he regards with almost pathetic veneration) on whose teaching, he says, the purest rules of Counterpoint are based. Of these authorities only one, and he by no means the greatest (Cherubini) has any connection at all with the history of music as an art. All the others were merely speculative theorists; men, such as Fux and Albrechtsbergerwho were quite out of touch with the real art even of their own day.

Indeed, many of the rules laid down by these old writers are so antiquated, that modern theorists have been almost compelled to modify them to some extent. Hardly any theorist now-a-days would have the hardihood to assert (for example) that Canti Fermi should be written in the old modes. But these well-meant attempts to bring the study up to date have really done much more harm than good. For, since the whole thing is founded merely on speculation, and not on the actual practice of composers, each man has felt perfectly free to alter it in accordance with his own ideas. The natural result is an extraordinary diversity of opinion among theorists. It is perfectly safe to say that no two text-books on Counterpoint agree in their teaching; and this disagreement is not so much on little trivial things as on really important points. It would be quite easy to fill several pages with examples of these conflicting statements; but there is really no need, as nobody can possibly have studied the subject without being struck by them. The differences among theorists are, indeed, notorious; but the cause of these differences has not hitherto been properly recognised. The cause is that there is nothing to appeal to-nothing that the various theories can be tested by; and one man, therefore, has as much right to lay down the law as another.

The other studies, which generally come later, such as Canon and Fugue, might seem at first sight to have rather more to do with real music, but the resemblance is only superficial. There is all the difference in the world between the ordinary theoretical 
The Study of Theory in Music Teaching. Is it Sound? 63

conception of Fugue and the same form in the hands of a great master like Bach. The one is simply an exercise in contrapuntal combination-about as dry and mechanical as anything well could be; the other is an art form. And this holds good of all the other more advanced contrapuntal studies, such as Double and Triple Counterpoint, Canon and Imitation. These things are devices which composers make use of occasionally-we might almost say incidentally -in the course of their works, and to study them separately is absurd. In any case the exercises which the student is called upon to work are utterly unlike any examples that are ever met with in real composition.

Most theorists will indeed admit this at once. "But," they will argue, "these studies are not intended as practice in actual composition; they are merely preparatory work-a species of mental gymnastics." Such an argument, carried out logically, would justify almost any course of study. There is probably no form of mental application which is absolutely useless (either to a music student or anyone else); and it might be provedsay - that a course of mathematics would be of use (in some remote and round-about way) as a preparation for musical composition. In defending our present theoretical course, it is not enough to prove that it has some value as mere mental training; the question is-has it any direct bearing on the study of music?

Not only, however, are these studies bad in the negative sense that they do no good, but they are also bad in the positive sense that they actually do harm. It is a commonplace of science that if any faculty is neglected for any length of time it will gradually grow weaker and weaker and in the end cease to exist. It is impossible for the student to spend a number of yearsand those too, generally the most impressionable years of his life-on these utterly barren and mechanical studies, without injury to his musical nature-his originality, imagination, and so forth.

It may be said that many famous composers have gone through such a course of study without apparently suffering much harm from it. It may be so; but then these were men of the highest musical powers, men whose genius was strong enough to triumph over the deadening influence of their early training; just as it was strong enough to triumph over many other obstacles. But because a few men of genius have succeeded in spite of an irrational system of training, that is surely no resson why the same or a similar system should be imposed upon others. About the only possible ground on which our present system can be 
defended is that it is a sort of Spartan method of weeding out all but the very fittest.

After all, the best test of any system is the practical one. We have only to ask the student fresh from a course in harmony and counterpoint, to write an accompaniment to a melody, or to do some other such simple thing bearing some resemblance to composition; and observe how utterly at sea he is. All the "rules" that he has learnt are somehow no help to him; he has no idea how far they apply to his new task-or, indeed, if they apply at all. By writing innumerable harmony and counterpoint exercises he has acquired a certain amount of skill; but, unfortunately, it is only skill in writing harmony and counterpoint exercises; for actual composition, or anything approaching to it, he is little, if any, better off-even in a technical sense-than he was at the beginning of his studies. One of our foremost composers, who is also a professor at one of our leading institutions, is in the habit of saying to his pupils when they go to him for the first lesson-" Now the first thing I want you to do is this: to forget all you have learnt." The advice is excellent; but the unfortunate pupil may be pardoned for wondering why-if his knowledge of theory was never to be of any use to him-he was ever required to acquire it at all.

Indeed, the more closely we consider the matter, the more evident it becomes that what is wanted is nothing less than a complete revolution in our methods of musical education. No tinkering or patching up can really do much good. Before considering what should take the place of our present system, it may be advisable to inquire more particularly what is fundamentally wrong with it. From such an inquiry we may possibly deduce those general principles that should-and indeed mustunderlie any rational course of musical education; and we shall therefore be in a better position to map out such a course.

II.

The object of our present training-so far as it can be said to have any clear object at all-is to afford the student some preparation for actual composition. But not only is this object (as we have seen) at the best only imperfectly realized; the oery idea is in itself vorong. It is wrong because it is based on an utterly wrong conception of education. Teachers and educationalists have come to the conclusion that the best possible test of any teaching is whether or no it is in accordance with the natural 
The Study of Theory in Music Teaching. Is it Sound? 65

process of development-as revealed in the unconscious workings of the minds of infants and animals. There is no need to enter here into any discussion as to the rightness or otherwise of this principle - the time has long since gone by for that; we merely take it for granted.

Let us then apply this test to the teaching of theory. Perhaps the closest possible analogy in nature to the student just beginning the study of composition is that of an infant just beginning to speak. The analogy, indeed, is about as close as could be: for not only is the student just as unable to express himself musically as the child is by speech, but neither, at the beginning, has really anything to express; the ideas of each-in the one case musical, in the other general-are so very vague that they can hardly be said to exist at all. For the sake of simplifying matters, however, we will first consider how the child actually learns to speak; that is to say, how it learns to articulate clearly-to pronounce the word it wants to (supposing that its mind is sufficiently developed to "want to"). On this point there is fortunately no doubt whatever; the child learns to speak simply by trying over and over again to speak; not by any artificial exercise of the muscles of articulation: and there is no resson to suppose that any such exercises would in any way facilitate the process. The general conclusion that this suggests is supported by everything that we know of in nature. To quote the words of Herbert Spencer, in his book on Education:

Everywhere throughout creation we find faculties developed through the performance of those functions which it is their office to perform; not through the performance of artificial exercises devised to fit them for those functions. The Red Indian acquires the swiftness and agility which make him a successful hunter by the actual purguit of animals. - . And similarly in all cases. From the Bushman whose eye, habitually employed in identifying distant objects that are to be pursued or fled from, has acquired a telescopic range, to the accountant whose daily practice enables him to add up several columns simultaneously; we find that the highest power of a function results from the discharge of those duties which the conditions of life require it to discharge. And we may be certain, a priori, that the same law holds good throughout education.

But further. The child, as we have seen, learns to speak simply by constant practice. But the quiestion may be asked"Why is it that the child ever tries to speak at all?" Without attempting to go at all deeply into the subject, one thing is fairly clear; and that is that the child learns to speak because 
it has somothing to say. Ideas are necessary to speech-this is self-evident-and it is only because the infant has ideas that it is capable of speech at all; so that the ideas are the motive force (as we may say) that produce the speech. Our present musical training, however, exactly reverses this natural order; its object is to provide the student with a fairly complete technical equipment first-as a preparation, it is to be supposed, for such time as he may have ideas to express-leaving the ideas to come after; this, of course, is simply putting the cart before the horse.

That the conclusion, too, which we have drawn from the analogy of nature is correct, is proved by the whole course of musical history. People did not find out how to express themselves in terms of music first, and then actually do so afterwards. It is only because they had ideas which they wished to express that they ever came to express them; and it was only by actually trying to express them that they ever learnt to do so. This is seen, if possible, even more clearly in the lives of the various composers. There is no instance of a musician acquiring a complete technique before beginning to compose. Each man had to find out for himself how he could best express his own particular ideas; and this he could only do by actually trying to express them.

But the true method of teaching is not only suggested by the analogy of nature; and the conclusions that may be drawn from the whole course of musical history, and the lives of the various individual composers; it is almost thrust upon teachers (if they would but see it) in the natural musical development of a child. Did not almost every great composer first attract attention to his gifts, when a child, by trying to pick out tunes on the piano, or in some such way? And what is more common than for a child of any real musical talent to make some attempts at composition? Of course, these early attempts are extremely crude and babyish; but that is not the question. The point is that the child has certain ideas - however vague they may be-which it is trying to express; and all that is really necessary is that the teacher should simply aid and guide this natural development. Unfortunately, what usually happens is that, as soon as the child has drawn attention to its natural talent, every possible care is taken to stifle that talent: all natural development is entirely checked, and its place is taken by an utterly irrational course of artificial training. It is really little wonder that $80 \mathrm{few}$ children of great musical talent ever fulfil their early promise; the only surprising thing is that any survive at all. 
III.

The application of the principles clearly implicit in the foregoing considerations is evident. Music teaching should be in almost all respects exactly the opposite of what it at present is. Instead of being dogmatic, it should be sympathetic and tentative; instead of seeking to split up into its constituent elements and present them to the student separately, it should aim at the general development of his musical nature; instead of trying to provide the student with an artificial technique long before he has anything to express, it should leave his technique to grow itself from his natural need of musical expression. It is obvious that this would carry with it great changes in the teaching of the so-called "practical" subjects (the only teaching that would in fact be given). Here we come on a wide field, and one, of course, into which it would clearly be impossible to attempt to enter fully here. But it may be said briefly that these subjects, one and all, would be taught less with a view to more particular technical excellence than to development of the pupil's general musical nature. That is to say, they should be taught so as to do for the student what the so-called "theoretical" studies are supposed to do for him at present. To say this, however, is perhaps after all only to say that the practical subject would be taught generally, as all best teachers at the present time do try to teach them.

It is, indeed, only when these subjects are taught rightly that any right teaching of composition becomes possible: for the study of composition would in the natural course of events grow out of them. If the pupil has any natural talent for composition (and it is, of course, only with such cases that we need deal) it will be sure to show itself, in various little attempts at selfexpression: and these attempts, instead of being checked or ignored, should be encouraged. It is not very easy to indicate, in so many words, the exact course that the teacher should pursue; but his general attitude may be best expressed by saying that he should endeavour to aid the natural development of the pupil, without in any way interfering with it. Anything approaching dogmatic teaching should be entirely avoided. It is quite impossible for any student, at an early stage, to understand and really appreciate the real meaning of any rules-that is to say the principles which underlie them; and to learn merely to observe the letter of the law, without this appreciation of its spirit, is worse than useless. The aim of the teacher should be to develop the pupil's musical sense; and the only way in which this can be 
done, is to constantly appeal to it directly. Thus, if the pupil is told that anything he has written is wrong because it is contrary to some rule or other, he is taught to substitute what is to him an altogether artificial standard for his natural musical sense, which is thereby (if only from non-use) weakened; whereas, if the teacher would only try to make him hear and feel for himself that what he has written is wrong, his natural musical sense would, instead, be strengthened and developed.

Not only would a technique be in this way acquired more easily and more quickly than it could possibly be by artificial means, but there is no comparison in the kind of technique; for while one would be exactly suited to the student's needs, the other could, at the best, only touch on them at one or two points, and then only imperfectly.

Of course, the success, in practice, of any such teaching as this, would depend to a very great extent on the teacher himself. It is here that the difficulty in the way of reform lies. For before anything can be done, we have to educate our educators, or rather, they must educate themselves. Things are, however, tending in the right direction. There is already a sort of dim and hazy recognition among teachers of practically all the principles that we have laid down; most of them, indeed,-however absurd they may possibly seem when presented in their bare form and pushed to their logical conclusion-are altogether too obvious to be entirely disregarded. But they need to be more fully and clearly recognized; and-above all-applied to actual teaching.

One word may perhaps be hazarded in conclusion. It is perhaps only when music takes its place definitely as part of our educational system that any right system of music teaching will become possible. But that is clearly too large a subject to ente: upon here. 